\title{
Burnout of Primary Teachers in Qatar Government Schools during an Era of Educational Reform
}

\author{
Maymona M. Alloh, Mahmood A. Hasan, \\ Xiangyun Du and Michael H. Romanowski \\ Qatar University \\ Doha, Qatar
}

\begin{abstract}
This study examined the burnout levels of a broad crosssectional sample of primary school teachers $(n=1657)$ from Qatar within the three domains of the burnout syndrome: Emotional Exhaustion (EE), Depersonalization (DP), and Personal Accomplishment (PA). Statistical analysis results indicated high levels of burnout reported by the participants (52.2\%) within the core dimension of burnout - Emotional Exhaustion (EE) dimension, indicating a high level of emotional overextension and exhaustion. Relatively low levels of burnout in the Depersonalization (DP) and Personal Accomplishment (PA) dimensions were identified. Geographical data analysis discovered significant differences among primary teachers' burnout level and nationality, gender, educational levels, and years of teaching experience in one or more dimensions. Nevertheless, there were no significant differences reported with teachers' educational level in any of the burnout dimensions. The results of the study provide implications for teachers' well-being and professional development in Qatar.
\end{abstract}

Keywords: Teachers' burnout; governmental primary schools; Qatar; Educational Reform.

\section{Introduction}

Teachers play a critical role in improving education quality and learning outcomes (OECD, 2005). Previous studies have noted a positive impact of teachers' well-being on students' outcomes and achievement, and in cases of teachers' sick leaves and absenteeism, and burnout students' outcomes may be influenced (Bricheno, Brown \& Lubansky, 2009; Klusmann et al. 2008; Maslach et al. 2001). The internationally recognized challenge regarding teachers' shortages has caused a recruitment problem. It may also degrade the quality of classroom instruction due to the high level of teachers' turnover, and one factor that impacts the teacher workforce internationally is the high rate of burnout (Chang, 2009; Duan, Du \& Yu, 2018; Judge et al. 2001; Santiago, 2002). Over the past two 
decades, a growing body of international literature has examined teachers' wellbeing in terms of stress, burnout, and job dissatisfaction (Klusmann et al. 2008; Maslah, Schaufeli \& Leiter, 2001; Yerdelen, Sungur \& Klassen, 2016). More specifically, previous studies suggested that among all levels of education, primary school teachers have reported higher burnout levels (Arvidsson et al., 2016; Paleksic, Ubovic \& Popovic, 2015; Yerdelen et al., 2016).

Qatar's government education system consists of four school levels: pre-school (age 3-5), primary (age 6-12, Grade 1-6), preparatory (Grade 7-9), and secondary levels (Grade 10-12). Primary level teachers occupy nearly half of the total number of teachers in Qatar (47.8\%) (MDPS, 2015). Primary education in Qatar is a female-dominated profession with an unequal gender distribution of 6316 female teachers $(96.3 \%)$ and 243 male teachers $(3.7 \%)$ in all primary government schools (MDPS, 2015). In addition, there is a pronounced dependence on Arabic speaking expatriate teachers in government schools in Qatar due to the shortages of Qatari teachers (Qatari 29.4\% and Expatriate 70.6\%) (Ridge, Shami, Kippels, \& Farah, 2014). Over the past decade, a series of educational reforms were initiated by the Ministry of Education and Higher Education (MOEHE) to improve the "underachievement of Qatari students in math, science and English language at all levels" (Al-Emadi et al., 2015, p. 16).

Concerning burnout in the context of Qatar's primary schools, with the extensive efforts by Qatar's leaders including changing the structure of the primary schools, establishing the curriculum standards and providing very high-quality school buildings and facilities, the role of teachers is critical to the successful implementation of education reform (Al-Emadi et al., 2014; Chaaban \& Du, 2017). Concerns were raised that primary teachers in Qatar were over exhausted because of the increased workload and changing goals of the educational reform (Al-Thani \& Nasser, 2012). However, little is known about the teachers' current situation, and thus, it is important to investigate primary teachers' well-being. Therefore, the purpose of this study is to examine primary school teachers' burnout levels in Qatar government schools and to gain insight into teachers' workplace conditions and perceptions of their jobs, which may provide sources for future initiatives to improve teachers' performance that would directly affect students' achievements and school competency.

\section{Literature review}

\subsection{Burnout - definition and conceptual understanding}

Definitions of burnout vary without an explicit agreement. In this study, we define burnout as an individual negative psychological experience that is related to discomfort, dysfunction, or adverse consequences (Maslach, Leiter \& Schaufeli, (2008). Maslach, Leiter \& Schaufeli, (2008)'s theoretical model is employed in the current study, which has identified three dimensions which have been confirmed as markers for burnout: Emotional Exhaustion (EE), Depersonalization (DP), and reduced Personal Accomplishment (PA). EE is viewed as the core domain of burnout and described as the feeling of wearing out, fatigue, losing of energy, always overwhelmed, stressed, and exhausted. DP is the change or shift in responses to others or clients such as depersonalization 
or an inappropriate attitude towards others. The reduced PA dimension is the negative self-evaluation towards oneself and one's achievements at work, indicating a low level of self-esteem.

Maslach, Leiter, and Schaufeli (2008) identified different paths to burnout. First, enthusiastic and dedicated workers are the ones who experience burnout because they work with great effort in agreement with their ideals. This leads them to a stage of exhaustion and then cynicism when they cannot achieve their aspirations and what satisfies their ideals (Maslach et al., 2008). Second, burnout is the final stage or the result of stressful job experiences extended over a period of time. Third, depersonalization is the first burnout dimension to occur, followed by reduced personal accomplishments, and then emotional exhaustion. An alternative way suggests that the burnout dimensions occur at the same time but independently. Another option may be that emotional exhaustion may be the first stage of burnout that leads to the development of the depersonalization dimension and then to the reduced personal accomplishments dimension. In general, a sequential link from emotional exhaustion to the depersonalization has been recognized. However, a subsequent link to the third dimension, PA, is varied and unclear (Maslah et al., 2001).

\subsection{Factors contributing to burnout}

Researchers usually propose individual, contextual, or organizational factors as an explanation for teacher burnout (Chang, 2009). The previous studies' findings of the individual factors, such as demographic variables (e.g., age, gender, years of teaching experience, teaching qualification, etc.) are not very consistent predictors of teachers' burnout (Chang, 2009). However, organizational factors, such as lack of autonomy, lack of administrative support, workplace environment, time pressure, showed more consistent results in increasing teachers' burnout (Chang, 2009; Scheuch, Haufe \& Seibt, 2015). Also, contextual variables, such as working hours, excessively large class sizes (Scheuch et al., 2015), students' misbehavior, discipline problems, and crowded classrooms showed more consistent results in developing teachers' burnout and weakening the idealism of teachers' function (Chang, 2009). Additionally, many work stressors such as demands on teachers, control over teachers' work, support for teachers, organizational change, and role conflicts or ambiguity were related to burnout (Maslach et al., 1981).

\subsection{Studies on teachers' burnout}

Extensive studies have been conducted internationally to explore the prevalence of burnout among teachers and identified a relationship between specific demographic variables and the individual's burnout experience. Several studies showed varied results regarding burnout levels among primary teachers. Primary school teachers in North Dakota in the United States (Mowers, 2010) and Turkey (Ozan, 2009) reported moderate levels of emotional burnout. However, primary school teachers reported lower levels of burnout in countries such as, Sweden (Arvidsson et al., 2016), Serbia (Ranđelović \& Stojiljković, 2015), the Republic of Srpska (Paleksic et al. 2015), Turkey (Yerdelen et al., 2016), Iraq (Soleman \& Edrees, 2007) and Sudan (Gumaiha, 2012). 
Several studies found an effect of gender, level of education, or years of experience on teachers' burnout levels and others not. For example, some studies found significant differences in burnout levels in at least one burnout dimension between female and male teachers favoring females (Arvidsson et al., 2016; Kabadayi, 2015; Kokkinos, 2007; Maslach \& Jackson, 1981). However, other studies found that male teachers suffer from burnout more than females in one or more burnout dimensions (Al-Ayasrah \& Abdel Rahman, 2013; Al-Farah, 2001; Gumaiha, 2012; Maslach \& Jackson, 1981). In contrast, several studies found no significant differences between female and male teachers within the three burnout dimensions (Bakhit \& Hassan, 2011; Dbaby, 2012; El-Omari \& Freihat, 2011; Ozan, 2009; Paleksic et al., 2015).

Regarding the nationality, very few studies explore the effect of teachers' nationality, whether local or foreigner, on their burnout levels. Al-Farah (2001) studied 122 special education teachers in Qatar and found that non-Qatari teachers suffered significantly higher than Qatari teachers. In contrast, Aljaroudi's (2015) study on 330 university teachers in Saudi Arabia found that local teachers (Saudis) scored higher levels of burnout within the EE and DP than foreign teachers (non-Saudis). However, both Saudi teachers and nonSaudis had relatively the same moderate level of PA burnout.

Concerning the teacher's level of education, some studies reveal a correlation between higher educational degrees and higher levels of Emotional Exhaustion (EE) and reduced personal accomplishments (Maslach \& Jackson, 1981). However, several studies showed no significant effect of the educational level on any of the burnout dimensions (Al-Frehat \& Al-Rabadi, 2010; Al-Mashikhy, 2013; El-Omari \& Freihat, 2011; Gumaiha, 2012).

Although some studies showed no main effect on the teachers' years of teaching experience (Al-Frehat \& Al-Rabadi, 2010; Dbaby, 2012; El-Omari \& Freihat, 2011; Gumaiha, 2012; Hammett, 2013; Kabadayi, 2015; Soleman \& Edrees, 2007), AlMashikhy (2013), Kokkinos (2007), Paleksic et al., (2015) found that the more experienced teacher, the higher the burnout level in at least one of the burnout dimensions. On the other hand, many studies showed that the younger the teacher or, the less experienced the teacher is, the higher the level of burnout in at least one of burnout dimensions (Goddard \& Goddard 2006; Hammett, 2013; Kabadayi, 2015; Maslach \& Jackson, 1981).

In summary, although teachers' burnout is not a new topic, results of previous studies remain inconclusive, without clear patterns on demographic variables such as gender, age, nationality, level of education, experience, as predictors of teachers' burnout. This suggests that societal and social context is an important factor influencing teachers' job satisfaction or burnout (Chaaban \& Du, 2017). In particular, in Qatar, it deserves research attention due to the constantly ongoing educational reforms in Qatari governmental primary schools. Therefore, this study aimed to explore teachers' burnout levels in Qatar by answering the following research questions: 
1) How do Qatari primary governmental school teachers report on levels and types of (psychological) burnout they have experienced?

2) How does the level of (psychological) burnout vary according to gender, nationality, level of education, and years of teaching experience?

\section{Research methods}

\subsection{Participants}

Participants of the study were teachers from Qatari primary governmental schools, which takes up nearly half $(47.8 \%)$ of the total number of teachers working at all levels of government schools in Qatar (MDPS, 2015). The questionnaire survey was administrated online via Survey Monkey, and the link was sent to all teachers working in governmental primary schools via an invitation email from a Ministry of Education and Higher Education (MOEHE) platform. The total population of primary teachers is 6559 distributed among 103 primary government schools (96\% female, $n=6316 ; 4 \%$ male, $n=243)$, working in 103 governmental primary schools (50 are for girls and 53 for boys) (MDP, 2015). A total of 1657 participants responded and completed the questionnaire. The valid response rate was roughly $25 \%$, which leads to (+-) $2 \%$ sampling errors.

Both the MOEHE and Qatar University ethically approved the study. Demographic data are shown in Table 1.

Table 1. Demographical data of participants

\begin{tabular}{llll}
\hline Characteristic & Levels & Frequency & Percent \\
\hline Gender & Female & 1412 & $85.2 \%$ \\
& Male & 245 & $14.8 \%$ \\
Nationality & & & \\
& Qatari & 505 & $30.5 \%$ \\
& Non-Qatari & 1152 & $69.5 \%$ \\
Level of education & Bachelor & 1425 & $86 \%$ \\
& Diploma & 125 & $7.5 \%$ \\
& Master or PhD & 107 & $6.5 \%$ \\
Years of Experience & Less than 5 years & 370 & $22.3 \%$ \\
& Between 5-10 years & 496 & $29.9 \%$ \\
& More than 10 years & 791 & $47.7 \%$ \\
\hline
\end{tabular}

\subsection{Research design and data collection}

A quantitative approach was employed in this study to gain insight into teachers' self-reported level of burnout, using a questionnaire survey which is an often-used method in the study of teachers' well-being (Scheuch et al., 2015).

The Maslach Burnout Inventory-Educators Survey (MBI-ES) was used as the data collection instrument. The MBI-ES is regarded as the most widely and extensively used instrument in measuring burnout (Aluja, Blanch \& García, 2005; Chang, 2009). The instrument was developed in 1981 (Maslach \& Jackson, 
1981) and further developed with revision without changes in the domains and items (Maslach et al., 2008).

The MBI-ES consists of 22 items in total and three subscales, which are the three components of the burnout syndrome. The Emotional Exhaustion (EE) (nine items) describe feelings of wearing out or loss of energy. The Depersonalization subscale (five items) describes the negative shift attitude towards students. The Personal Accomplishment subscale (eight items) describes the positive response toward oneself and one's successful personal achievements in work. The items are based on a 7-point frequency rating scale, ranging from "never" (0) to "every day" (6). The questionnaire has been implemented in Omani, Saudi, Iraqi, Algerian and Jordanian schools with a reliability coefficient above 0.70 (AlAyasrah \& Abdel Rahman, 2013; Al-Farah, 2001; Dbaby, 2012; El-Omari \& Freihat, 2011; Soleman \& Edrees, 2007).

\subsection{Validity and Reliability of the instrument in an Arabic context}

\subsubsection{Content validity}

The English version of the MBI-ES (Maslach et al., 2008) was translated into Arabic. The translated version was compared to Arabic versions previously translated in the above-mentioned studies and also validated by three professors in the field of psychology who speak both English and Arabic. Since the term burnout has been perceived differently among people and in order to minimize the sensitive effect of one's beliefs or prospects of such a concept, the scale manual emphasizes that the participants should not be informed that the MBI is a burnout measure. Instead, "the scale should be presented as a survey of jobrelated attitudes and not be linked to burnout in any way" (Maslach et al., 1997, p. 196).

\subsubsection{Constructive validity}

The 22 items were subjected to the confirmative factor analysis using principal components analysis as the extraction technique, followed by the Varimax rotation method to ensure the constructive validity of a survey with the three factors for measuring Burnout of Primary Teachers (Emotional Exhaustion, Depersonalization, and Personal Accomplishment). As suggested by Hasan, M. \& Fong, S. (2014), the Kaiser-Meyer-Olkin's test and Bartlett's test of sphericity were calculated to assure the suitability of the data for factor analysis. The results of the tests show that Kaiser-Meyer-Olkin's measure of sampling adequacy test is 0.936, and Bartlett's Test of Sphericity was significant, $\chi^{2}=$ 17358.6, $\mathrm{p}<.000$, which means that the underlying factors would very well predict the items. The significant level of Bartlett's test of sphericity being 0.00 also indicates that the data are appropriate for factor analysis, and then confirmative factor analysis with rotation was performed. Factor loadings were estimated using primary component analysis, and rotations were performed using Varimax method. Three constructs have Eigenvalues greater than 1, and the remaining constructs with Eigenvalues less than 1 are ignored. (Hasan, M. and Fong, S., 2014). The results are as presented in Table 2. 
Table 2. Extraction Method: Principal Component Analysis for Burnout of Primary Teacher

Total Variance Explained

\begin{tabular}{|c|c|c|c|c|c|c|}
\hline \multirow[b]{3}{*}{ Component } & \multicolumn{2}{|c|}{ Initial Eigenvalues } & \multicolumn{2}{|c|}{$\begin{array}{l}\text { Extraction Sums of } \\
\text { Squared Loadings }\end{array}$} & \multicolumn{2}{|c|}{$\begin{array}{l}\text { Rotation Sums of } \\
\text { Squared Loadings }\end{array}$} \\
\hline & $\%$ of & Cumulative & $\%$ of & Cumulative & $\%$ of & Cumulative \\
\hline & tTotal Variance & $\%$ & TotalVariance & $\%$ & TotalVariance & $\%$ \\
\hline 1 & 8.02836 .490 & 36.490 & 8.02836 .490 & 36.490 & 4.22919 .223 & 19.223 \\
\hline 2 & 2.63211 .962 & 48.453 & 2.63211 .962 & 48.453 & 4.08518 .569 & 37.792 \\
\hline 3 & 1.3366 .074 & 54.527 & 1.3366 .074 & 54.527 & 3.68216 .735 & 54.527 \\
\hline
\end{tabular}

Extraction Method: Principal Component Analysis.

Table 3 shows the rotated factor matrix for Burnout of Primary Teacher and the questionnaire items used to measure the three factors of Burnout of Primary Teacher. As shown in Table 3, the items now are loaded well on their respective factors.

Table 3. Rotated Factor Matrix for Burnout of Primary Teacher and Its Items

\begin{tabular}{llll}
\hline \multicolumn{4}{l}{ Components } \\
& 1 & 2 & 3 \\
\hline Item 1 & 0.775 & 0.233 & -0.101 \\
Item 2 & 0.813 & 0.076 & -0.072 \\
Item 3 & 0.786 & 0.278 & -0.142 \\
Item 4 & 0.549 & 0.054 & -0.123 \\
Item 5 & 0.634 & 0.501 & -0.146 \\
Item 6 & 0.514 & 0.059 & -0.249 \\
Item 7 & 0.600 & -0.036 & 0.033 \\
Item 8 & 0.500 & 0.056 & -0.136 \\
Item 9 & 0.382 & 0.057 & -0.167 \\
Item 10 & 0.111 & 0.644 & -0.206 \\
Item 11 & 0.430 & 0.640 & -0.166 \\
Item 12 & 0.048 & 0.631 & -0.176 \\
Item 13 & -0.013 & 0.655 & -0.222 \\
Item 14 & -0.022 & 0.640 & -0.047 \\
Item 15 & 0.058 & -0.109 & 0.619 \\
Item 16 & -0.015 & -0.118 & 0.690 \\
Item 17 & -0.052 & -0.075 & 0.673 \\
Item 18 & -0.309 & -0.353 & 0.579 \\
Item 19 & -0.127 & -0.276 & 0.723 \\
Item 20 & -0.137 & -0.284 & 0.680 \\
Item 21 & -0.002 & -0.098 & 0.695 \\
Item 22 & -0.236 & 0.027 & 0.482 \\
\hline
\end{tabular}

See Appendix 1 for complete items 
Table 3 presents the results of the three factors. Items (1-9) making up the first factor and addressed the Emotional Exhaustion with loading between 0.3830.813 . These nine items accounted for $19.223 \%$ of the variance. The second factor addressed Depersonalization in items (10-14) and had loading between 0.6550.631 . These five items accounted for $18.57 \%$ of the variance. The third factor, Personal Accomplishment, had items (15-22) and loading between 0.432- 0.723 with $16.73 \%$ of the variance. The total survey explained $54.53 \%$ of the variance. The results in Tables $(2 \& 3)$ present that the Burnout of Primary Teacher questionnaire has a good validity.

\subsubsection{Reliability}

To ensure instrument reliability, internal consistency for the instrument was measured using the Cronbach-alpha coefficient. The result shows that (with participants $\mathrm{N}=1657$ ) the Cronbach-alpha coefficient for $\mathrm{EE}$ factor $=0.899$, for $\mathrm{DE}=0.777$, and for $\mathrm{PA}=0.809$. Based on these values, the instrument is valid, and the internal consistency coefficients are approximately similar to those reported in the initial study by Maslach and Jackson (1981) with human service workers as participants (Cronbach-alpha coefficient for $\mathrm{EE}=0.89$, for $\mathrm{DP}=0.77$, and for $\mathrm{PA}=0.74$, respectively).

\section{Analysis and results}

Descriptive statistics, including means, standard deviations, and frequencies were calculated for each domain individually using the Statistical Package for the Social Sciences software (SPSS) 25. Independent-samples T-test was conducted to compare the means of demographic characteristics, including gender and nationality on the three burnout dimensions, and also One-way ANOVA was conducted to compare the means of level of education and years of teaching experience.

\subsection{Question one}

To answer question one, "How do Qatari primary governmental school teachers report on levels and types of (psychological) burnout they have experienced?" each subscale is measured according to the guidelines in a scoring key made by the scale developers (Maslach, 1997). Interpretation of scores for each subscale follows Emotional Exhaustion: Low Burnout: 0-16, Moderate Burnout 17-26, Higher burnout +27 . Depersonalization: Low Burnout: 0-6, Moderate Burnout 712, Higher burnout +13 . Personal Accomplishment used reversed scale, with low burnout category scores indicating low levels of dissatisfaction with PA: Low Burnout: +37, Moderate Burnout 31-36, Higher burnout 0-30.

Table 4 presents descriptive statistics of the participants' scores on the three dimensions of MBI-ES. Participants' mean score in the EE domain corresponds to the high level of burnout category $(\mathrm{M}=28.09, \mathrm{SD}=13.90)$ while the $\mathrm{DP}(\mathrm{M}=$ $5.86, \mathrm{SD}=6.82)$ and $\mathrm{PA}(\mathrm{M}=41.46, \mathrm{SD}=6.68)$ domains are within the low levels of burnout. 
Table 4. Means of burnout dimensions compared with MBI-ES

\begin{tabular}{|c|c|c|c|c|}
\hline Domains & \multicolumn{2}{|c|}{ MBI Scoring Key } & Participants' & Standard \\
\hline \multirow{3}{*}{ Emotional Exhaustion (EE) } & Low & $0-16$ & & \multirow{3}{*}{13.90} \\
\hline & Moderate & $17-26$ & & \\
\hline & High & +27 & 28.09 & \\
\hline \multirow{3}{*}{ Depersonalization (DP) } & Low & $0-6$ & 5.86 & \multirow{3}{*}{6.82} \\
\hline & Moderate & $7-12$ & & \\
\hline & High & +13 & & \\
\hline \multirow{3}{*}{ Personal Accomplishment (PA) } & Low & $37+$ & 41.46 & \multirow{3}{*}{6.68} \\
\hline & Moderate & $31-36$ & & \\
\hline & High & $0-30$ & & \\
\hline
\end{tabular}

Table 5 outlines the percentages of participants within each burnout domain. Results indicated that $52.2 \%$ participants are within the high level of EE burnout $\left(\chi^{2}=267.5, \mathrm{p}<.000\right)$, while $65.2 \%$ of participants are within low level of DP domain $\left(\chi^{2}=756.5, \mathrm{p}<.000\right)$. for the PA domain, $82.7 \%$ participants are within the low levels of dissatisfaction $\left(\chi^{2}=1822.2, \mathrm{p}<.000\right)$.

Table 5. Participants' percentage burnout level score with Chi Square values.

\begin{tabular}{lllll}
\hline & Low & Moderate & High & $\begin{array}{l}\text { Chi } \\
\text { square }\end{array}$ \\
\hline Emotional Exhaustion & $24.4 \%$ & $23.4 \%$ & $52.2 \%$ & $267.5^{*}$ \\
Depersonalization & $65.2 \%$ & $18 \%$ & $16.8 \%$ & $756.5^{*}$ \\
Personal Accomplishment & $82.7 \%$ & $10.1 \%$ & $7.2 \%$ & $1822.2^{*}$ \\
\hline
\end{tabular}

* Significant at 0.01 for the highest value of burnout level

\subsection{Question two}

To answer question two, "How does the level of (psychological) burnout vary according to gender, nationality, level of education, and years of teaching experience? a t-test and ANOVA were used.

\subsubsection{Teachers' reported burnout level by gender}

In order to explore the significant differences between male and female on the three burnout dimensions, independent-samples t-test was used. Table 6 presents results of a t-test. Descriptive statistics shows that female teachers scored higher level of burnout on the three burnout measures; EE, DP, and PA $(M=29.01, S D=13.88 ; M=5.97 S D=6.90$ and $M=41.38, S D=6.76$, respectively) than male teachers $(M=26.84, S D=13.84 ; M=5.74, S D=6.32$ and $M=41.55, S D=6.58$, respectively). T-test results shows that the EE burnout levels was significantly different between female and male teachers at $\alpha=0.05$, $(t=3.146, p<.002)$. However, no significant differences were noted between 
female and male teachers on the DP burnout levels $(t=0.649, p=.516)$, and the PA burnout levels $(t=-.0521, p=.602)$.

Table 6. Analysis of gender and burnout levels (with $d f 1=1$ and $d f 2=1655$ )

\begin{tabular}{lllllc}
\hline Burnout domains & $\begin{array}{l}\text { Descriptive } \\
\text { statistics }\end{array}$ & $\begin{array}{l}\text { Female } \\
(\mathrm{n}=1412)\end{array}$ & $\begin{array}{l}\text { Male } \\
(\mathrm{n}=245)\end{array}$ & $\mathrm{t}$ & p-value \\
\hline EE & Mean & 29.01 & 26.84 & \multirow{2}{*}{3.146} & .002 \\
& SD & 13.88 & 13.84 & & \\
DP & Mean & 5.97 & 5.74 & 0.649 & 0.516 \\
& SD & 6.90 & 6.32 & & \\
PA & Mean & 41.38 & 41.55 & -0.521 & .602 \\
& SD & 6.76 & 6.58 & & \\
\hline
\end{tabular}

\subsubsection{Teachers' reported burnout level by nationality}

Table 7 presents results of t-test to determine the differences between teachers' nationality on the three burnout dimensions. Teachers' nationality is divided into two levels: Qatari and Non-Qatari teachers. Qatari teachers scored significantly higher level of burnout within the three burnout measures compared to Non-Qatari at $\mathrm{a}=0.05$. For $\mathrm{EE}, \quad(\mathrm{M}=34.88, \mathrm{SD}=13.70 ; \mathrm{M}=$ $25.11 \mathrm{SD}=12.91$, respectively, $\mathrm{t}=11.81, \mathrm{p}=0.00)$. For $\mathrm{DP}, \quad(\mathrm{M}=8.26, \mathrm{SD}=$ 7.95; $\mathrm{M}=4.81, \mathrm{SD}=5.97$ respectively, $\mathrm{t}=6.68, \mathrm{p}=0.000)$ and for $\mathrm{PA},(\mathrm{M}=$ $39.66, \mathrm{SD}=7.68, \mathrm{M}=24.42, \mathrm{SD}=6.03$ respectively, $\mathrm{t}=7.37, \mathrm{p}=0.00$ ).

Table 7. Analysis of nationality and burnout levels (with $\mathrm{df}=1655$ )

\begin{tabular}{|c|c|c|c|c|c|}
\hline Burnout domains & $\begin{array}{l}\text { Descriptive } \\
\text { statistics }\end{array}$ & $\begin{array}{l}\text { Qatari } \\
(\mathrm{n}=505)\end{array}$ & $\begin{array}{l}\text { Non- } \\
\text { Qatari } \\
(\mathrm{n}=1152)\end{array}$ & $\mathrm{t}$ & $\mathrm{p}$-value \\
\hline \multirow[t]{2}{*}{$\mathrm{EE}$} & Mean & 34.88 & 25.11 & & \\
\hline & SD & 13.702 & 12.91 & 11.81 & .000 \\
\hline \multirow[t]{2}{*}{ DP } & Mean & 8.26 & 4.81 & & \\
\hline & SD & 7.95 & 5.97 & 6.68 & 0.000 \\
\hline \multirow[t]{2}{*}{ PA } & Mean & 39.66 & 24.42 & & \\
\hline & SD & 7.68 & 6.03 & 7.37 & 0.000 \\
\hline
\end{tabular}

\subsubsection{Teachers' reported burnout level by educational backgrounds}

Table 8 presents the results of a one-way ANOVA to determine the differences among teachers' educational levels on the three burnout dimensions. Teaches' educational level is divided into three levels: bachelor, diploma and Master or $\mathrm{PhD}$ holders. ANOVA results shows that there are no significant differences among all educational levels on the all three burnout dimensions. For EE burnout level, among all educational levels: bachelor, diploma and Master or PhD holders, $[M=28.09, S D=13.90$; and $M=28.55, S D=13.84$, and $M=$ $27.56, S D=14.06$ respectively $, F(2,1655)=0.146, p=.864]$. For DP burnout 
level, among all educational levels: bachelor, diploma and Master or $\mathrm{PhD}$ holders, $[M=5.83, S D=6.77$; and $M=5.77, S D=7.33$, and $M=6.40, S D=6.90$ respectively, $F(2,1654)=0.361, p=0.697]$. Regarding the differences among all educational levels: bachelor, diploma and Master or PhD holders on the PA level, the ANOVA results shows that $[M=41.49, S D=6.56$; and $M=41.95, S D=$ 6.71 , and $M=40.43, S D=8.09$ respectively $, F(2,1654)=1.62, p=0.197]$.

Table 8. analysis of the educational level and burnout levels (with $d f 1=2$ and $d f 2=1654$ )

\begin{tabular}{lllllll}
\hline $\begin{array}{r}\text { Burnout } \\
\text { domains }\end{array}$ & $\begin{array}{c}\text { Descriptive } \\
\text { statistics }\end{array}$ & $\begin{array}{c}\text { Bachelor } \\
(\mathrm{n}=1452)\end{array}$ & $\begin{array}{c}\text { Diploma } \\
(\mathrm{n}-125)\end{array}$ & $\begin{array}{c}\text { Master or } \\
\text { PhD } \\
(\mathrm{n}=107)\end{array}$ & $\mathrm{F}$ & p-value. \\
\hline EE & Mean & 28.09 & 28.55 & 27.56 & & \\
& SD & 13.90 & 13.84 & 14.06 & .146 & .864 \\
DP & Mean & 5.83 & 5.77 & 6.40 & & \\
& SD & 6.77 & 7.33 & 6.90 & .361 & .697 \\
PA & Mean & 41.49 & 41.95 & 40.43 & & \\
& SD & 6.56 & 6.71 & 8.09 & 1.62 & .197 \\
& & & & & & \\
\hline
\end{tabular}

\subsubsection{Teachers' reported burnout level by years of teaching experiences}

Table 9 presents the results of a one-way ANOVA to determine the differences among teachers based on their years of teaching experience on the levels of burnout dimensions. Teachers' years of experience are divided into three levels: less than 5 years, between 5 and 10 years, and more than 10 years of teaching experience. F-test and LSD post hoc test show that, teachers with less than 5 years of experience and teachers with more than 10 years of experience scored higher in their EE burnout levels $[M=28, S D=13.27$; and $M=28.91, S D=14.28$, respectively) than teachers with experience between 5 and 10 years $(M=$ $26.85, S D=13.67, F(2,1654)=3.354, \mathrm{p}=0.035)]$. ANOVA results also show that there are no significantly differences among teachers' years of experience on DP and PA burnout levels $[F(2,1654)=.431, \mathrm{p}=0.650, F(2,1654)=.052, \mathrm{p}=0.950)$ respectively ]

Table 9. Analysis of teaching experience and burnout levels(with $d f 1=2$ and $d f 2=1654$ )

\begin{tabular}{lllllll}
\hline $\begin{array}{l}\text { Burnout } \\
\text { domains }\end{array}$ & $\begin{array}{c}\text { Descriptive } \\
\text { statistics }\end{array}$ & $\begin{array}{c}\text { Less than } \\
5 \text { years } \\
(\mathrm{n}=370)\end{array}$ & $\begin{array}{c}\text { Between 5- } \\
10(\mathrm{n}=496)\end{array}$ & $\begin{array}{c}\text { More than } \\
10 \text { years } \\
(\mathrm{n}=791)\end{array}$ & $\mathrm{F}$ & $\begin{array}{c}\mathrm{p} \\
\text { value }\end{array}$ \\
\hline EE & Mean & 28 & 26.85 & 28.91 & 3.35 & .035 \\
& SD & 13.24 & 13.67 & 14.28 & & \\
DP & Mean & 6.14 & 5.72 & 5.82 & & \\
& SD & 6.92 & 6.83 & 6.77 & .431 & .650 \\
& & & & & & \\
PA & Mean & 41.36 & 41.49 & 41.48 & .950 & .950 \\
& SD & 6.41 & 6.32 & 7.02 & & \\
\hline
\end{tabular}




\section{Discussion}

This study examined the burnout levels of a broad cross-sectional sample of primary school teachers $(n=1657)$ from Qatar within the three domains of the burnout syndrome: Emotional Exhaustion (EE), Depersonalization (DP), and Personal Accomplishment (PA). Statistical analysis results indicated high levels of burnout reported by the participants $(52.2 \%)$ within the core dimension of burnout - Emotional Exhaustion (EE) dimension, indicating a high level of emotional overextension and exhaustion, but relatively low levels of burnout in the Depersonalization (DP) and Personal Accomplishment (PA) dimensions. Geographical data analysis results revealed significant differences between primary teachers' burnout level and gender, nationality, educational level, and years of teaching experience in one or more dimensions. Nevertheless, no significant differences were found with teachers' educational level in any of the burnout dimensions.

The high level of EE burnout found aligns with previous studies conducted with primary school teachers such as Dbaby's (2012) study on primary school teachers in Algeria and different school levels in Jordan (Al-Ayasrah \& Abdel Rahman, 2013; Al-Frehat \& Al-Rabadi, 2010; El-Omari \& Freihat, 2011). The mean score of the EE burnout was found to be higher than those reported on primary school teachers in different countries such as Iraq (Soleman \& Edrees, 2007), Sudan (Gumaiha, 2012), Sweden (Arvidsson et al., 2016), Serbia (Ranđelovi \& Stojiljković, 2015), North Dakota in the United States (Mowers, 2010), Turkey (Ozan, 2009; Yerdelen et al., 2016), and the Republic of Srpska (Paleksić et al., 2015).

Many factors could be related to teachers' burnout. One of the major assumed reasons is low salaries and income for teachers (Al-Ayasrah \& Abdel Rahman, 2013; Dbaby, 2012). In addition, pupils' attitudes, behavior, and motivation have been found as causes that may lead to teachers' stress and burnout (Burke \& Greenglass, 1993; El-Omari \& Freihat, 2011). This is relevant to Qatar with a high rate of unmotivated students and an urgent need to motivate children (The QNDS, 2011). Students' low motivation in classes can generate stress and frustration for teachers with their lack of attention and disruptive behavior (Chaaban \& Du, 2017; Du, Chaaban \& ALMabrd, 2019; Nasser \& McInerney, 2014).

Another factor that may have a significant effect on primary teachers' burnout levels in Qatar is numerous changes in the educational system. Organizational change may affect teachers' well-being and cause stress and reduced work satisfaction due to the increased workload and changed goals (Arvidsson et al., 2016; Chaaban \& Du, 2017). In Qatar, teachers are under pressure and feeling unsure of how to meet the goals of the curriculum and the national professional standards for teachers (Al-Thani \& Nasser, 2012). Other factors identified by teachers in a change process such as lack of resources and collaboration among teachers, rigid administrative practices (Chaaban \& Du, 2017; Du, Chaaban \& ALMabrd, 2019) may also add to their stress. This indicates that educational change and reforms should consider the time teachers need to adjust in order to 
increase the chance to succeed since teachers' motivation and well-being is highly essential (Du, Chaaban \& ALMabrd, 2019).

The mean scores of the DP reveal low levels of burnout that is in line with several studies (Arvidsson et al., 2016; Gumaiha, 2012; Mowers, 2010; Paleksic et al., 2015; Ranđelovi \& Stojiljković, 2015; Soleman \& Edrees, 2007; Yerdelen et al., 2016). In addition, the low PA burnout level found to be lower than those reported by primary school teachers in Algeria (Dbaby, 2012) and Turkey (Ozan, 2009). The mean score of the PA was found to be lower than results from previous studies on primary school teachers in Australia (Goddard \& Goddard, 2006), Algeria (Dbaby, 2012), Turkey (Ozan, 2009), Iraq (Soleman \& Edrees, 2007), Sudan (Gumaiha, 2012), Sweden (Arvidsson et al., 2016), Serbia (Ranđelovi \& Stojiljković, 2015), Turkey (Yerdelen et al., 2016) and the Republic of Srpska (Paleksic et al., 2015).

Although participants in this study showed high levels of EE burnout, there are notable low levels of burnout in the other two dimensions, DP and PA. Interestingly, across a wide range of examinations of burnout syndrome, it can be argued that the EE burnout is strongly correlated to the DP or cynicism dimension of burnout syndrome (Maslach et al., 2008). However, the results of this study revealed that participants had high levels of burnout in the EE but low levels in the DP dimension. This case of "incompatibility" (Maslach et al., 2008, p. 99) between EE and DP are found in other studies (Goddard \& Goddard, 2006) that could be explained in two ways. Firstly, it has been reported that some teachers may have "feelings" of burnout in which they feel emotionally exhausted, drained, or wearing out but they may still feel satisfied, efficacious about teaching tasks, and have a positive attitude towards students (Chang, 2009; Du, Chaaban \& ALMabrd, 2019). Secondly, the accumulated empirical evidence suggests that burnout is a process that gradually develops across time (Maslach \& Leiter, 1996; Schaufeli \& Peeters, 2000), in which the EE is recognized as the first stage of the burnout process while the DP or the negative attitudes towards students is the second stage (Schaufeli \& Peeters, 2000). Therefore, the results of this study may support the developmental model that suggested that each dimension of burnout leads to the development of the other starting from the EE toward the PA. Besides, a strong predictor of future individual change is anticipated in which the two domains may move towards consistency over time (Maslach et al., 2008). This means that early notice of stress and burnout might help to improve their job satisfaction (Duan, Du \& Yu, 2018; $\mathrm{Du}$, Chaaban \& ALMabrd, 2019) and prevent the prevalence of the syndrome.

Results from this study indicate that female teachers reported high levels of EE burnout while male teachers were at a moderate level. However, there is no difference between females and males in the other two dimensions of burnout; both are within the low levels of DP and PA burnout dimensions. The female over male on reported EE burnout was inconsistent with the results in the initial study that developed the burnout inventory (Maslach \& Jackson, 1981). The literature remains elusive whether gender has an effect on teachers' stress and burnout. While some studies revealed that female teachers tend to be affected by emotional exhaustion more than male teachers (Arvidsson et al., 2016; Kabadayi, 
2015; Kokkinos, 2007), some studies report that male teachers are more emotionally drained than female teachers (Al-Ayasrah \& Abdel Rahman, 2013; Al-Farah, 2001; Bricheno et al., 2009; Gumaiha, 2012), and other studies found no effect of the gender variable on the burnout level (Bakhit \& Hassan, 2011; Dbaby, 2012; El-Omari \& Freihat, 2011; Ozan, 2009; Paleksic et al., 2015). Previous literature did not corroborate a pattern of gender and burnout level, and there are no previous studies in Qatar that provided reasons for gender differences.

Teachers' nationalities in this study showed a significant difference between Qatari and non-Qatari teachers within the three dimensions of burnout. Qatari teachers scored remarkably higher levels of EE burnout than non-Qatari teachers. Many studies have shown that low salaries lead to elevated burnout levels. However, that was not the case in this study. Some reports revealed that Qatari teachers are the highest paid in the Arab world. Additionally, Qatari teachers have several bonuses and allowance for the years of experience, qualifications and for the gained points from the evaluation at the end of the year yet the burnout level is still high, and the schools in Qatar suffer from high rate of shortages of both female and male Qatari teachers (Alkhateeb, 2013; Ridge et al., 2014). This result may be related to the low respondent rate of Qatari teachers $(30.5 \%)$. Although non-Qatari teachers reported lower burnout levels than Qatari teachers, the reported moderate burnout level still deserves attention because they take up $70.6 \%$ of the teacher population. Although nonQatari teachers earn higher salaries than what is usually earn in their home countries, they confront several challenges in Qatar, such as unstable job contracts (Ridge et al., 2014) and lack of respect from Qatari students (AlMohannadi \& Capel, 2007). In relation to previous studies, Aljaroudi (2015) reported similar results in that the Saudi teachers scored higher levels of burnout than non-Saudis. Nevertheless, Al-Farah (2001) found that non-Qatari special education teachers suffered from burnout more than Qatari teachers. On the other hand, Al- Mohannadi and Capel (2007) found that Qatari and nonQatari physical education teachers scored relatively the same levels of stress. The difference regarding burnout and nationality gives insight that this area should be further researched. The general lack of agreement on comparing teachers' burnout reported by local and expatriate teachers calls for more attention in future studies to obtain more evidence and to explore reasons through qualitative data.

The current study reports no significant differences between the three education levels of teachers and their burnout level. This outcome is inconsistent with the results of Maslach and Jackson's study (1981) and Hammett (2013), who found that the higher the level of education was associated with the higher the level of EE burnout. Also, Maslach and Jackson (1981) and Tashtoush et al. (2013) revealed that the higher teachers' educational level, the higher the EE burnout. Nevertheless, several studies found no notable differences in the three dimensions' results of the three teacher groups in previous studies (Al-Frehat \& Al- Rabadi, 2010; Al-Mashikhy, 2013; El-Omari \& Freihat, 2011; Gumaiha, 2012). This indicates a lack of agreement in the current literature with the original studies, which suggests a need for more studies to validate this aspect. 
Results show that both novice (less than five years of teaching experiences) and experienced teachers (between five and ten years, and more than ten years of teaching experiences) reported high levels of EE burnout. Previous studies do not show a clear pattern regarding this aspect. While several studies espouse the argument that the burnout most of the time accrued in the early stage of teachers' job (Goddard \& Goddard, 2006; Kabadayi, 2015; Maslach \& Jackson, 1981), some studies contradict this observation and asserts that the burnout tends to be related to their job satisfaction (Duan, Du \& Yu, 2018) and occur later in teachers' work-life (Al-Mashikhy, 2013; Kokkinos, 2007; Paleksic et al., 2015). In addition, several studies reveal that teachers' years of experience had no effect on teachers' burnout levels (Al-Frehat \& Al- Rabadi, 2010; Dbaby, 2012; ElOmari \& Freihat, 2011; Gumaiha, 2012; Hammett, 2013; Kabadayi, 2015; Soleman \& Edrees, 2007).

In Qatar, the ongoing substantial educational reform may impact both novice and experienced teachers. The experienced teachers who have more than ten years of teaching experience may find it difficult to cope with the organizational changes and reform demands such as digital technology use and its implications on the curriculum and pedagogical practices comparing to their teaching lives before the reform. For novice teachers, they began teaching during the reform in which the job demands are high, and they may not be prepared to deal and cope with stress (Chaaban \& Du, 2017).

The study has several limitations. First, data sources of the study are mainly relying on a self-reported questionnaire survey, although it provides an overall picture of the government primary school teachers' burnout situation in Qatar, reasons of these patterns may have been better explained through in-depth qualitative interviews. Further, the results of the study may be compared with other perspectives; for example, school administrators, leaders, and students. In addition, although the study received a significant number of respondents, the distribution was uneven. For example, only $30 \%$ of the Qatari teacher population responded. Moreover, the differences in the results of the current study and other studies may be due to many other different individual and organizational factors. Since the current study's sample and analysis are limited to primary school teachers, it deserves future attention to include a broader group of teachers beyond governmental primary schools. Also, studies to better understand how work environments can help teachers better cope with their challenges will also bring further insights into the field.

\section{Conclusion}

To summarize, there were significant differences between primary teachers' burnout level and demographic variables such as gender, nationality, and teaching experience. However, no significant differences found between the burnout level and teachers' level of education. In general, only if teachers maintain healthy mental and emotional states and strive to identify and effectively cope with various job stressors and when school administrators provide teachers with continuous and comprehensive support from their first year of teaching, they are likely to hold positive attitudes towards the 
profession, provide their students with a caring and nurturing learning environment, and become active participants in the improvement of curricular, assessment, and pedagogical practices at their schools.

\section{References}

Al-Ayasrah, M., \& Abdel Rahman, A. (2015). Levels of burnout among teachers: males and females in Jerash directorate of education in light of some variables. $P h D$ Proposal, 1. doi:10.1017/CBO9781107415324.004

Al-Emadi, D., Al-Emadi, A., Diop, A., Trung Le, K., Kimmel, L., Wittrock, J., \& Zikri, S. (2014). Qatar education study 2012: Curriculum report. Doha, Qatar. Retrieved from http://sesri.qu.edu.qa/web/publications/

Al-Emadi, D., Al-Emadi, A., Diop, A., Trung Le, K., Kimmel, L., Wittrock, J., \& Al Bloshi, A. (2015). Qatar education study 2012 facilities report. Retrieved from http://sesri.qu.edu.qa/web/publications/

Al-Farah, A. (2001). Psychological burnout among professionals working in special education settings in state of Qatar. Dirasat, 28(2), 247-271.

Al-Frehat, A., \& Al-Rabadi, W. (2010). The level of psychological burnout among the teachers of the Kinder Gardens in Ajloun Governorate. An-Najah University Journal for Research-Humanities, 24(5).

Aljaroudi, M. (2015). Burnout levels for faculty members when coping academic accreditation requirements in the college of education at King Saud University. Educational and Psychological Sciences Journal, 16(2).

Alkhateeb, H. M. (2013). Attitudes towards teaching profession of education Innovative Teaching, 2, 1-5. doi:10.2466/01.03.IT.2.9

Al-Mashikhy, G. (2013). Psychological burnout and its relation to the quality of life among primary school teachers in Taif Governorate. Majallat 'Alam Al-Tarbiyah, 41. doi:10.1017/CBO9781107415324.004

Al-Mohannadi, A., \& Capel, S. (2007). Stress in physical education teachers in Qatar. Social Psychology of Education, 10(1), 55-75. doi:10.1007/s11218-006-9004-9

Al-Thani, A., \& Nasser, R. (2012). Little steps at improving preschool teachers' practices through counseling skills in Qatar. International Education Studies, 5(5), 163-172. doi:10.5539/ies.v5n5p163

Aluja, A., Blanch, A., \& García, L. F. (2005). Dimensionality of the Maslach Burnout Inventory in school teachers: A study of several proposals. European Journal of Psychological Assessment, 21(1), 67-76. doi:10.1027/1015-5759.21.1.67

Arvidsson, I., Håkansson, C., Karlson, B., Björk, J., \& Persson, R. (2016). Burnout among Swedish school teachers-a cross-sectional analysis. BMC Public Health, 16(1), 823. doi:10.1186/s12889-016-3498-7

Bakhit, S., \& Hassan, Z. (2011). Burnout among teachers of gifted students in the Sudan. Umm Al-Qura University Journal of Educational \& Psychological Sciences, 3(1), 12-68.

Bricheno, P., Brown, S., \& Lubansky, R. (2009). Teacher Wellbeing: A Review of the Evidence. Retrieved from https://www.scribd.com/doc/25759578/Teacher-Wellbeing-Aresearch-of-the-evidence

Chang, M. L. (2009). An appraisal perspective of teacher burnout: Examining the emotional work of teachers. Educational Psychology Review, 21(3), 193-218. doi:10.1007/s10648-009-9106-y

Chaaban, Y., \& Du, X. (2017). Novice teachers' job satisfaction and coping strategies: Overcoming contextual challenges at Qatari government schools. Teaching and Teacher Education, 67, 340-350. doi:10.1016/j.tate.2017.07.002

Dbaby, B. (2012). The level of the psychological burnout among primary teachers in Ouargla. Journal of Humanities and Social Sciences, 9(1).

doi:10.1017/СBO9781107415324.004 
Du, X., Chaaban, Y., \& ALMabrd, Y. M. (2019). Exploring the concepts of fidelity and adaptation in the implementation of project based learning in the elementary classroom: Case studies from Qatar. International Journal of Learning, Teaching and Educational Research, 18(9), 1-22. doi:10.26803/ijlter.18.9.1

Duan, X., Du, X., \& Yu, K. (2018). School Culture and School Effectiveness: The Mediating Effect of Teachers' Job Satisfaction. International Journal of Learning, Teaching and Educational Research, 17(5). P15-25. doi:10.26803/ijlter.17.5.2

El-Omari, A., \& Freihat, A. (2011). Burnout levels of Jordanian teachers of English in Ajloun Province. Journal of Al-Quds Open University for Research and Studies, 24(2).

Goddard, R., \& Goddard, M. (2006). Beginning teacher burnout in Queensland schools: Associations with serious intentions to leave. The Australian Educational Researcher, 33(2), 61-75. doi:10.1007/BF03216834

Gumaiha, A. (2012). The psychological burnout among of boy's teachers in governmental schools in Omdurman locality and its relationship with self-esteem and other demographic variables. Omdurman Islamic University, Sudan.

Hammett, J. (2013). Examining teacher burnout using intelligence quotients: A correlational study. Texas A\&M University.

Hassan, M. \& Fong (2014). E-learning modules supported by cooperative learning: Impact on Arabic language achievement among Qatar University students. Near and Middle Eastern Journal of Research in Education. 2012(1). Retrieved from http://www.qscience.com/doi/abs/10.5339/nmejre.2012.1

Judge, T. A., Thoresen, C. J., Bono, J. E., \& Patton, G. K. (2001). The job satisfaction-job performance relationship: A qualitative and quantitative review. Psychological Bulletin, 127, 376-407.

Kabadayi, A. (2015). Investigating the burn-out levels of Turkish preschool teachers. Procedia - Social and Behavioral Sciences, 197(February), 156-160. doi:10.1016/j.sbspro.2015.07.073

Klusmann, U., Kunter, M., Trautwein, U., Lüdtke, O., \& Baumert, J. (2008). Teachers' occupational well-being and quality of instruction: The important role of selfregulatory patterns. Journal of Educational Psychology, 100(3), 702-715. doi:10.1037/0022-0663.100.3.702

Kokkinos, C. M. (2007). Job stressors, personality and burnout in primary school teachers. British Journal of Educational Psychology, 77, 229-243. doi:10.1348/000709905X90344

Maslach, C., \& Jackson, S. (1981). The measurement of experienced Burnout. Journal of Occupational Behavior, 2(2), 99-113. doi:10.1002/job.4030020205

Maslach, C., Jackson, S. E., \& Leiter, M. P. (1997). The Maslach Burnout Inventory: Manual. In Evaluating Stress (3rd ed., p. 29). London: The Scarecrow Press, Inc.

Maslach, C., Leiter, M., \& Schaufeli, W. (2008). Measuring burnout (3rd ed.). NY: Psychology Press.

Maslach, C., Schaufeli, W. B., \& Leiter, M. P. (2001). Job burnout. Annual Review of Psychology, 52, 397-422.

MDPS. (2015). Education Statistics. Retrieved from http://www.arabdevelopmentportal.com/sites/default/files/publication/873. qatar-education_statistics_2014.pdf

Mowers, E. (2010). Teacher Burnout in North Dakota. North Dokota State University.

Nasser, R., \& McInerney, D. (2014). Achievement-oriented beliefs and their relation to academic expectations and school achievement among Qatari students. Educational Psychology, 36(7), 1219-1241. doi:10.1080/01443410.2014.993928

OECD. (2005). Teachers Matter: attracting, developing and retaining effective teachers. Retrieved from https://www.oecd.org/edu/school/34990905.pdf

Ozan, M. B. (2009). A study on primary schoolteacher burnout levels: The Northern Cyprus case. Education, 129(4), 692-703. Retrieved from http:/ / www.redi- 
bw.de/db/ebsco.php/search.ebscohost.com/login.aspx?direct=true\&db=aph\& AN $=40310163 \&$ site $=$ ehost-live

Paleksic, V., Ubovic, R., \& Popovic, M. (2015). personal characteristics and burnout syndrome among teachers of primary and secondary schools. Scripta Medica, $46(2)$.

QNDS. (2011). Qatar National Development Strategy 2011 2016. Retrieved from http://www.mdps.gov.qa/en/knowledge/HomePagePublications/Qatar_NDS _reprint_complete_lowres_16May.pdfRanđelović, K., \& Stojiljković, S. (2015). Work climate, basic psychological needs and burnout syndrome of primary school teachers and university professors. ЈА - РОДИТЕЉ, (179002), 823-845.

Ridge, N., Shami, S., Kippels, S., \& Farah, S. (2014). Expatriate teachers and education quality in the Gulf Cooperation Council (Policy Paper, 11). Ras Al-Khaimah, United Arab Emirates: Sheikh Saud bin Saqr Al Qasimi Foundation

Santiago, P. (2002). Teacher demand and supply: Improving teaching quality and addressing teacher shortages, OECD Education Working Paper, No. 1 OCED, Paris. Retrieved from www.oecd.org/edu/working papers

Schaufeli, W. B., \& Peeters, M. C. W. (2000). Job stress and burnout among correctional officers: A literature review. International Journal of Stress Management. 7 (1): 1948. doi:10.1023/A:1009514731657

Scheuch, K., Haufe, E., \& Seibt, R. (2015). Teachers' Health. Deutsches Ar̈zteblatt International, 112(20), 347-56. doi:10.3238/arztebl.2015.0347

Soleman, S., \& Edrees, A. (2007). Burnout of kindergarten female teachers in Nineweh. College of Basic Education Researches Journal, 4(1). doi:10.5866/2013.521323

Tashtoush, R., Jarwan, A., Muhaidat, M., \& Bni-Atta, Z. (2013). Burnout and the Level of Job Satisfaction and their Relationship among Resource Rooms Teachers in Jordan. An-Najah University Journal for Research - Humanities, 27(8).

Yerdelen, S., Sungur, S., \& Klassen, R. M. (2016). Relationship between Turkish elementary science teachers' occupational well-being and some contextual and demographic characteristics: A multivariate analysis. Egitim ve Bilim, 41(183), 147-161. doi:10.15390/EB.2016.4257

\section{Appendix 1}

Maslach Burnout Inventory-Educators Survey (MBI-ES) Items

1. I feel emotionally drained from my work.

2. I feel used up at the end of the workday.

3. I feel fatigued when I get up in the morning and have to face another day on the job.

4. Working with people all day is really a strain for me.

5. I feel burned out from my work.

6. I feel frustrated by my job.

7. I feel I'm working too hard on my job.

8. working with people directly puts too much stress on me.

9. I feel like I'm at the end of my rope.

10. I feel I treat some students as if they were impersonal objects.

11. I've become more callous toward people since I took this job.

12. I worry that this job is hardening me emotionally.

13. I don't really care what happens to some students.

14. I feel students blame me for some of their problems. 
15. I can easily understand how my students feel about things.

16. I deal very effectively with the problems of my students.

17. I feel I'm positively influencing other people's lives through my work.

18. I feel very energetic.

19. I can easily create a relaxed atmosphere with my students.

20. I feel exhilarated after working closely with my students.

21. I have accomplished many worthwhile things in this job.

22. In my work, I deal with emotional problems very calmly.

Reference: (Maslach \& Jackson, 1981; Maslach et al., 2008). 